\title{
Global Climate Change and the Production of "Pequi" Fruits (Caryocar brasiliense) in the Brazilian Cerrado
}

\author{
João Carlos Nabout ${ }^{1, *}$, Gislene Oliveira ${ }^{2}$, Mara Rúbia Magalhães², \\ Levi Carina Terribile ${ }^{3}$ \& Francisco Alberto Severo de Almeida ${ }^{2}$
}

\author{
${ }^{1}$ Universidade Estadual de Goiás, Unidade Universitária de Anápolis (UnUCET), Anápolis, GO, Brazil \\ ${ }^{2}$ Universidade Estadual de Goiás, Unidade de Educação a Distância (UnUEAD), Anápolis, GO, Brazil \\ ${ }^{3}$ Universidade Federal de Goiás - Campus Jataí, Jataí, GO, Brazil
}

\begin{abstract}
Several recent studies have predicted decreased environmental suitability for species in future scenarios of climate change, which will affect the economy of many municipalities. The aim of this study was to evaluate the impact of global climate change on environmental suitability for "Pequi" tree (Caryocar brasiliense; an economically important Cerrado fruit tree) and investigate the relationship between environmental suitability (according to an ecological niche model - ENM) and production of "Pequi" fruit in Brazilian cities. For the ENM, we used 312 occurrence points of "Pequi" tree and nine climatic variables to model current distribution and project it into future scenarios (scenario A2a for CCCma AOGCM). "Pequi" production averaged $30.89 \mathrm{~kg} / \mathrm{km}^{2}$, and the Gross Internal Product at municipal level and "Pequi" production were negatively but marginally correlated $(r=-0.16$; $P=0.05$ using Dutilleul's correction for spatial autocorrelation), suggesting that poor municipalities tend to have more use of this natural resource. Future scenarios showed large losses of suitable environments for the species in 2050 in Central Brazil. There is also a significant positive correlation between environmental suitability in current time and "Pequi" production across municipalities $(r=0.382, P=0.032)$. Our results suggest that municipality currently using "Pequi" fruit will have lower production in the future, because their regions will be less suitable for "Pequi" tree, which in turn may affect the local economies. Thus, it is necessary that governments develop policies that mitigate adverse impacts, enhance positive impacts, and supports adaptation to climate change, together with enhancing local food security.
\end{abstract}

Key words: Ecological Niche Model, Maxent, Environmental Suitability, Economic Impact.

\section{Introduction}

The study of climate change is not a new topic in the scientific community (Parmesan 2006), but the biological consequences of global warning have recently gained widespread notoriety, mainly because of its popularity in mass media. Several decades of research have accumulated strong evidence of the impacts of recent accelerated warming on many biological systems (e.g., Parmesan 2006, Elith \& Leathwick 2009), including temporal fluctuations in species distribution, population abundance, and community structure (Diniz-Filho et al. 2010; Beaumont et al. 2007). Not least of these are the effects on the biological diversity and ecosystem services, with potentially serious implications for food security (Walther et al. 2002).

\footnotetext{
*Send correspondence to: João Carlos Nabout

Universidade Estadual de Goiás,

Unidade Universitária de Anápolis (UnUCET),

BR-153, 3105, CEP 75132-903, Anápolis, GO, Brasil

E-mail: naboutjc@hotmail.com
}

The impact of climate change on species, including changes in its geographical distribution or its biological characteristics (such as intensity of fruiting or flowering), can directly affect human populations, in particular when such species are used in a biologically sustainable way and thus contribute to the maintenance of biodiversity and the economic activities at local scales (Reid et al. 2010). While most of studies have examined the impact of climate change on biological characteristics and geographical distribution of species at regional or global scales (see review in Elith \& Leathwick 2009; Parmesan 2006), few studies have hitherto explicitly investigated the effect of climate changes on species which exploitation represents the principal source of income for smallholder and subsistence agriculture at local scales (e.g., Morton 2007). The sustainable exploitation of natural resources is an important strategy of livelihood for rural communities, mainly in developing countries (Gupta 1997). For instance, changes in the actual geographic distribution 
of some native species may jeopardize their sustainable exploitation for traditional human communities in the future, thus bringing important risks for local economic development.

In the Cerrado biome, several plant species have been exploited by rural populations, including the endemic "Pequi" tree (Caryocar brasiliense). This species is exploited for the oil contained in the pulp mesocarp and the kernel of the seed. The seeds are habitually consumed in the culinary of the Cerrado region and their use is deeply rooted in the regional culture and cooking (Almeida et al. 1998).

Based on the cultural and economic importance of the "Pequi" tree for local human populations of Cerrado, the aim of this study was to evaluate the impact of global climate change on environmental suitability for "Pequi" tree and how this change may potentially affect the production of "Pequi" fruits (hereafter "Pequi" production) in the future. More specifically, we aim to i) investigate the relationship between "Pequi" production and environmental suitability under current climatic conditions, to determine if this environmental suitability can be used as a surrogate for the amount of "Pequi" exploitation and; ii) predict the future environmental suitability for this species in those municipalities that currently exploit the "Pequi" production, considering future scenarios of climate change. The results presented here could be used to identify which Cerrado regions are prone to reduce their "Pequi" production in the face of climate change, and also provide a comprehensive assessment of the economic viability of this species for subsistence of rural communities in the future.

\section{Material and Methods}

\section{The species}

"Pequi" tree (Caryocar brasiliense Camb., Caryocaraceae) is widely distributed in the Cerrado biome, occurring frequently in grasslands and Cerrado sensu stricto dystrophic vegetations (Ratter et al. 2003). The fruit of "Pequi" is divided into pericarp and putamen (mesocarp and endocarp), and each part has different uses (see Table S1 in the Additional supporting information at www.abecol.org.br; see also Oliveira 2009).

\section{Exploitation and economy of municipalities extracting Pequi}

The data of "Pequi" production in the Brazilian municipalities were obtained from the Brazilian Institute of Geography and Statistics (IBGE; www.ibge.gov.br) using their website's automatic system recovery (SIDRA) and "Vegetal Extraction" collection methods. We identified a total of 150 municipalities from all Brazilian regions (Figure 1) for which the production of "Pequi" have been recorded over ten years (from 2000 to 2009). For each municipality we calculated the average annual production, and as these municipalities have different geographic areas, we also weighted the average production of each municipality by its geographic area, according to IBGE. Thus, the average production of "Pequi" fruits per municipality was given as kilograms per square kilometer $\left(\mathrm{kg} / \mathrm{km}^{2}\right)$. We also obtained the Gross Internal Product (GIP for the year 2009) for each municipality to investigate possible conflicts between "Pequi" conservation and intensive agriculture. This is expected since the municipalities with highest GIP in the Cerrado biome are also those that have the largest proportion of lands converted to agriculture.

\section{Ecological niche model}

We used Ecological Niche Modeling (ENM) to obtain the environmental suitability of "Pequi" tree in the Cerrado biome in the present, and for future scenario. For this, we obtained 312 points of occurrence of "Pequi" tree (Figure 1), based on data from the literature and the Reference Center of Environmental Information (http://www.cria.org.br/).

Nine climatic variables were used in the ENM: 1) maximum temperature in the warmest month;2) minimum temperature in the coldest month; 3) annual temperature variation; 4) annual precipitation; 5) precipitation in the driest month; 6) precipitation in the wettest month; 7) standard deviations of rainfall; 8) mean maximum temperature; and 9) mean minimum temperature. The same variables were used to project the ENM into future climate, derived from the global climate model CCCma (Canadian Centre for Climate Modelling and Analysis) for a pessimistic scenario (A2a) for 2050. The climatic data were obtained from Wordclim

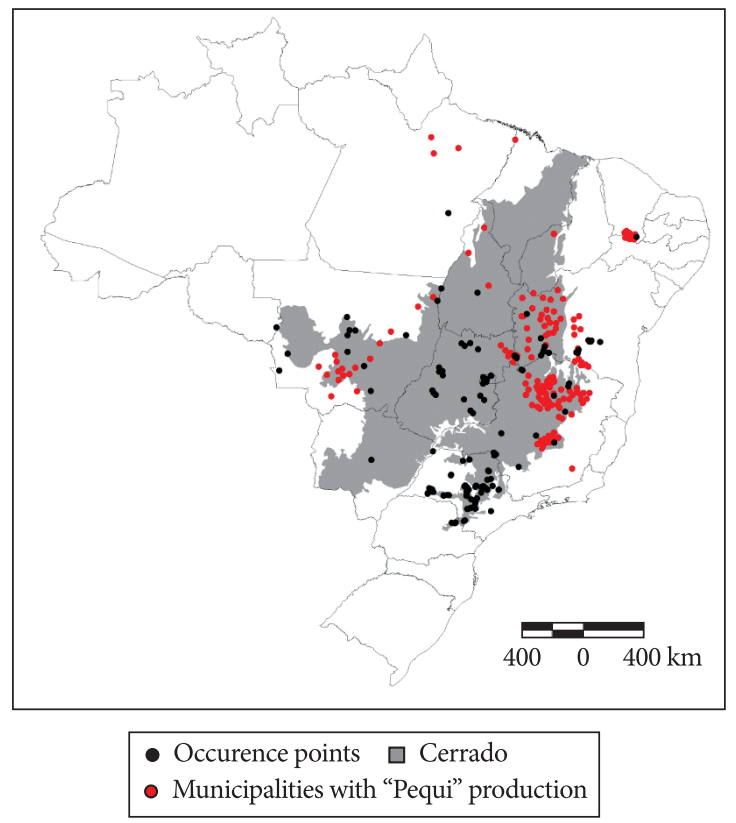

Figure 1. Geographic distribution of the data used in the analyses. Black dots indicate "Pequi" tree occurrences used for the Ecological Niche Model, whereas red dots indicate municipalities that produce "Pequi" fruits, according to IBGE data. 
(www.wordclim.org), and all the climate variables were converted into a grid with 0.0417 degrees of resolution.

ENM were obtained using the MaxEnt method (Phillips et al. 2006). The input parameters followed the program defaults, apart from the iterations that were set to 1000, with duplicates removed. We used the AUC (area under the curve) to evaluate the models (Elith et al. 2006).

\section{Data analysis}

The association between "Pequi" production and local environmental suitability was investigated using Pearson's correlation. Prior to analysis, both variables were $\log$-transform $(\log \mathrm{X}+1)$ to normalize the statistical distributions. We also used Pearson's correlation to test the relationship between log-transformed values for GIP and "Pequi" production. The significance test for these correlations were based on the geographically effective degrees of freedom obtained using Dutilleul's (1993) correction. All tests were performed in SAM v.4 Software (Rangel et al. 2010).

\section{Results}

The average "Pequi" production from all municipalities was $30.89 \mathrm{~kg} / \mathrm{km}^{2}$. The municipality with the highest production was "Lontra" (526.09 kg/ $\left.\mathrm{km}^{2}\right)$, whereas "Santa Fé de Minas" had the smallest values $\left(0.03 \mathrm{~kg} / \mathrm{km}^{2}\right)$. However, it is noteworthy that most municipalities (i.e. 126 municipalities) produced less than $50 \mathrm{~kg} / \mathrm{km}^{2}$ (Figure 1S in the additional supporting information). GIP and "Pequi" production were negatively correlated $(r=-0.16 ; P=0.05$ with 138 geographically effective degrees of freedom).
The ENM for current climate and for future scenario showed satisfactory adjustment, with $\mathrm{AUC}=0.98$. Also, a large portion of the Cerrado showed a relatively high environmental suitability in the current climate. Moreover, "Pequi" production and environmental suitability were positively correlated $(\mathrm{r}=0.382 ; P=0.032$ with 29 geographically effective degrees of freedom) (Figure 4), which suggest that the environmental suitability may be a surrogate for "Pequi" production.

However, in the future scenario, the suitability of those areas is widely reduced (Figure 2a,b). Indeed, according to the ENM generated here, in future scenarios most municipalities that currently produce "Pequi" fruits will lose suitability (Figure 3). Out of the 150 municipalities in our database, more than 30 will have environmental suitability scores reduced to values close to 0 . By considering environmental suitability as a surrogate of "Pequi" production, our results pose substantial evidence that this activity may no longer be economically viable for many rural communities in the future.

\section{Discussion}

\section{ENM and "Pequi" production}

ENM have been widely used in the scientific literature (Elith \& Leathwick 2009), mainly for modeling species distribution for many applications. In addition, researchers have investigated the relationship between environmental suitability obtained from these models and genetic population structure (Diniz-Filho et al. 2009a), functional traits (Thuiller 2010) and population density (Van Der Wal et al. 2009).

In this study, we investigated the relationship between environmental suitability and "Pequi" production. Our
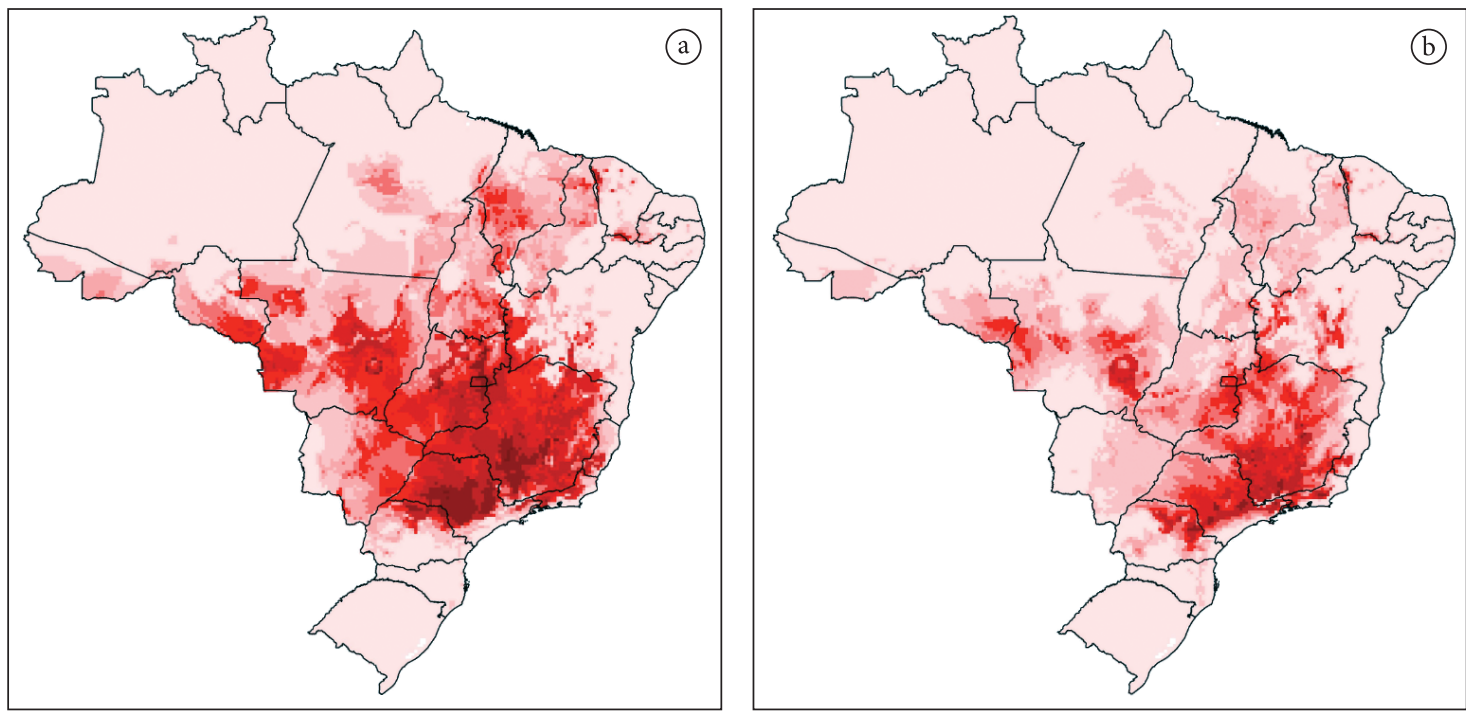

Suitability

$\square 0.0-0.1 \quad \square 0.1-0.2 \quad \square 0.2-0.3 \quad \square 0.3-0.4 \quad \square 0.4-0.5$

$0.5-0.6$

$0.6-0.7$

$0.7-0.8$

$0.8-0.9$

$0.9-1.0$

Figure 2. Map of environmental suitabilities of Caryocar brasiliense, generated using Maxent ENM for current time (a) and projected into 2050 (b) climatic scenario. 
result suggest that environmental suitability can be used as surrogate of "Pequi" production, and also, for density or species' abundance (or at least density of fruits produced). However, it is important to note that this relationship can be better described a constraint envelope and not as a functional relationship, where regions of low suitability will always minimally produce "Pequi" fruits, whereas highly suitable regions can produce more or less fruits depending on other ecological or economical factors (Figure 4). This may reduce the predictive ability of a model (i.e., for using to predict fruit production under future climates). Even so, the envelope suggests that, given its environmental suitability, some municipalities exploit "Pequi" below their potential production. However, the low production of "Pequi" in areas of high suitability may also be related to the low occurrence or even absence of "Pequi" trees in some regions. The species may be absent from a given site due to historical reasons or biotic interactions, not modeled by overall climatic bio-envelopes as used here (Hirzel et al. 2002). Indeed, as the Cerrado has undergone an intense process of land conversion for grazing and agriculture, it is possible that the intense anthropic activity have eliminated the "Pequi" tree populations from regions of high suitability (Sawyer 2008).

Alternatively, although numerous individuals of this species may occur in these regions (as suggested by high suitabilities), it is possible that the low production is related to low support to sustainable exploitation by local governments, thus making the production of other crops (such as soybean and sugar cane) a more profitable investment. This is partially supported by the relationship between GIP and "Pequi" production, which was very low and negative, demonstrating that the exploitation of "Pequi" tree has little importance in the GIP of municipalities. However, this may be important because poor municipalities, with low GIP, possess higher production of "Pequi" fruits, and this will be probably reduced in the future because of shifts in the distribution of climatically suitable areas (see below). Also, the weak correlation may suggest future conflicts for "Pequi" tree conservation in those regions of high suitability (Hannah et al. 2005), since the richest municipalities also present the highest conversion of lands (Gorenflo \& Brandlon 2006).

\section{Global changes and "Pequi" production}

Climate change, as well as its effects on biodiversity, has been the subject of intense debate in the literature, and many papers have investigated the impact of global warming on species distribution, frequently using ENMs (Araújo \& Luoto 2007; Elith \& Leathwick 2009; Diniz-Filho et al. $2009 b$ ). According to our results, a reduction in suitable environments for "Pequi" tree in future scenarios is expected. Moreover, those municipalities that currently produce "Pequi" will suffer a drop in production, given the reduction of the environmental suitabilities in some regions. However, it is important to note that our findings are conservative because other variables related to the maintenance of viable population of this tree, such as land use and soil composition,

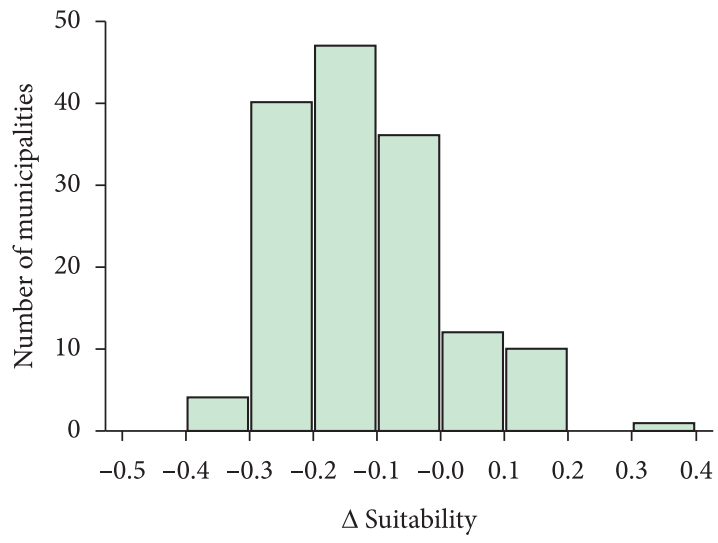

Figure 3. Histogram of the change in "Pequi" tree suitability, according to Maxent, with negative values indicating loss of suitability.

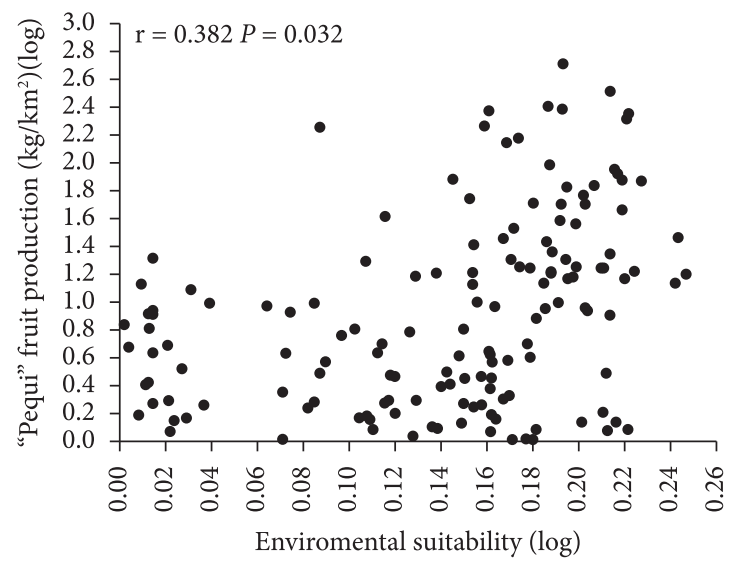

Figure 4. Relationship between the environmental suitability and the "Pequi" production for 150 municipalities.

as well as biotic interactions (i.e., loss of pollinators or seed dispersers), were not considered (Hannah et al. 2002).

Regarding the economic impacts of climate change, the most important aspect is the loss of suitable habitats in those municipalities whose "Pequi" production is an important source of income in rural areas. Consequently, the sustainable exploitation of "Pequi" may no longer be a source of livelihood for rural families in the future, thus leading to an increase of the poverty levels if other alternatives are not available. In fact, some studies have presented substantial indicators that developing countries will bear the brunt of the adverse consequences from climate change (e.g., Grossmann et al. 2009). Thus, the analyses carried out here for "Pequi" are important as the first step in understanding the impacts of global change on agriculture and natural resources. Along with this, it is necessary that governments develop policies that mitigate adverse impacts, enhance positive impacts, and supports adaptation to climate change, together with enhancing local food security (Reid et al. 2010; Grossmann et al. 2009; Garcia \& Araújo 2010). 
Finally, this study also highlights the importance of developing proactive conservation strategies for economically important species, as in the case of "Pequi". It may also help developing strategies for sustainability production of this and other species from Cerrado, under scenarios of climate change, allowing understanding their limits of exploitation in the future.

\section{Acknowledgements}

This work was developed under the research network GENPAC (Geographical, Genetics and Regional Planning for natural resources in Brazilian Cerrado) supported by $\mathrm{CNPq} / \mathrm{MCT} / \mathrm{CAPES}$ (project 563727/2010-1). Work by JCN, GO, MRM and FASA has been supported by UAB fellowships.

\section{References}

Almeida SP et al., 1998. Cerrado: espécies vegetais úteis. Planaltina: Embrapa-CPAC.

Araújo MB \& Luoto M, 2007. The importance of biotic interactions for modelling species distributions under climate change. Global Ecology and Biogeography, 16:743-753. http:// dx.doi.org/10.1111/j.1466-8238.2007.00359.x

Beaumont LJ et al., 2007. Where will species go? Incorporating new advances in climate modelling into projections of species distributions. Global change biology 13:1368-1385. http:// dx.doi.org/10.1111/j.1365-2486.2007.01357.x

Diniz-Filho JAF et al., 2009a. Niche modelling and landscape genetics of Caryocar brasiliensis (Pequi tree: Caryocaraceae) in Brazilian Cerrado: an integrative approach for evaluating central-peripheral population patterns. Tree Genetics \& Genomes, 5:617-627. http://dx.doi.org/10.1007/ s11295-009-0214-0

Diniz-Filho JAF et al., 2009b. Conservation biogeography and climate change in the Brazilian Cerrado. Natureza \& Conservação, 7:100-112.

Diniz-Filho JAF et al., 2010. Ensemble forecasting shifts in climatically suitable areas for Tropidacris cristata (Orthoptera: Acridoidea: Romaleidae). Insect Conservation and Diversity, 3:213-221.

Dutilleul P, 1993. Modifying the $t$-test for assessing the correlation between two spatial processes. Biometrics, 49:305-314. http://dx.doi.org/10.2307/2532625

Elith J \& Leathwick JR, 2009. Species distribution models: ecological explanation and prediction across space and time. Annual Review of Ecology, Evolution, and Systematics, 40:677-697. http://dx.doi.org/10.1146/annurev. ecolsys.110308.120159

Elith J et al., 2006. Novel methods improve prediction of species' distributions from occurrence data. Ecography, 29:129-151. http://dx.doi.org/10.1111/j.2006.0906-7590.04596.x

Garcia RA \& Araújo MB, 2010. Planejamento para a conservação em um clima em mudança. Natureza \& Conservação, 8:78-80.

Gorenflo LJ \& Brandon K, 2006. Key human dimensions of gaps in global biodiversity conservation. BioScience, 56:723-731. http://dx.doi.org/10.1641/0006-3568(2006)56[723:KHDO $\mathrm{GI}] 2.0 . \mathrm{CO} ; 2$

Grossmann WD et al., 2009. Indicators on economic risk from global climate change. Environmental Science and Technology, 15:6421-6426. http://dx.doi.org/10.1021/es8035797
Gupta, J, 1997. The climate change convention and developing countries: from conflicts to consensus? Netherlands: Kluwer Academic Publishers.

Hannah L et al., 2002. Climate change-integrated conservation strategies Global Ecology and Biogeography, 11: 485-495. http://dx.doi.org/10.1046/j.1466-822X.2002.00306.x

Hannah L et al., 2005. The view from the Cape: Extinction risk, protected areas, and climate change. BioScience, 55:231-242. http://dx.doi.org/10.1641/0006-3568(2005)055[0231:TVFT $\mathrm{CE}] 2.0 . \mathrm{CO} ; 2$

Hirzel AH et al., 2002. Ecological-niche factor analysis: how to compute habitat-suitability maps without absence data? Ecology, 83:2027-2036.

Morton, JF, 2007. The impact of climate change on smallholder and subsistence agriculture. Proceedings of the National Academy of Sciences, 104:19680-19685. PMid:18077400. PMCid:2148357. http://dx.doi.org/10.1073/pnas.0701855104

Oliveira WL. 2009. Ecologia populacional e extrativismo de frutos de Caryocar brasiliense Camb. no cerrado no Norte de Minas Gerais. [Dissertação de mestrado]. Brasília: Programa de Ecologia, Universidade de Brasília.

Parmesan C, 2006. Ecological and evolutionary responses to recent climate change. Annual Review of Ecology, Evolution and Systematics, 37:637-690. http://dx.doi.org/10.1146/ annurev.ecolsys.37.091305.110100

Phillips SJ et al., 2006. Maximum entropy modeling of species geographic distributions. Ecological Modeling, 190:231-259. http://dx.doi.org/10.1016/j.ecolmodel.2005.03.026

Rangel et al., 2010. SAM: a comprehensive application for Spatial Analysis in Macroecology. Ecography, 31:46-50. http://dx.doi.org/10.1111/j.1600-0587.2009.06299.x

Ratter et al., 2003. Analysis of the floristic composition of the Brazilian Cerrado vegetation. III: comparison of the woody vegetation of 376 areas. Edinburgh Journal of Botany, 60:57-109. http://dx.doi.org/10.1017/S0960428603000064

Reid WV et al., 2010. Earth system science for global sustainability: grand challenges. Science 330:916-917. PMid:21071651. http://dx.doi.org/10.1126/science.1196263

Sawyer D, 2008. Climate change, biofuels and eco-social impacts in the Brazilian Amazon and Cerrado. Philosophical Transactions of the Royal Society B, 363:1747-1752. PMid:18267903. PMCid:2373893. http://dx.doi.org/10.1098/ rstb.2007.0030

Thuiller W et al., 2010. Variation in habitat suitability does not always relate to variation in species' plant functional traits. Biology Letters, 23:120-123. PMid:19793738. PMCid:2817270. http://dx.doi.org/10.1098/rsbl.2009.0669

Van Der Wal J et al., 2009. Abundance and the environmental niche: environmental suitability estimated from niche models predicts the upper limit of local abundance. The American Naturalist, 174:282-291. PMid:19519279. http:// dx.doi.org/10.1086/600087

Walther et al., 2002. Ecological responses to recent climate change. Nature, 416:389-395. PMid:11919621. http://dx.doi. org/10.1038/416389a

Received: April 2011

First Decision: May 2011

Accepted: June 2011 
